\title{
Effects of Renal Denervation from the Intima and the Adventitia of Renal Arteries on Renal Sympathetic Nerve Activity in Dogs: A Comparative Study
}

\author{
Minfu Bai ${ }^{a}$ b Chaokuan Yang ${ }^{c}$ Chuanyu Gao ${ }^{a}$ Xianpei Wang ${ }^{a}$ Hongzhi Liu $^{a}$ \\ You Zhang ${ }^{\mathrm{a}}$ Jun Liu ${ }^{\mathrm{a}}$ Jintao $\mathrm{Wu}^{\mathrm{a}}$ Dongdong Jian ${ }^{\mathrm{a}} \mathrm{Lijie} \mathrm{Zhu}^{\mathrm{a}}$ Wenli Zhao ${ }^{\mathrm{a}}$ \\ Peiyao Ma ${ }^{b}$ Yaqi Han ${ }^{a}$

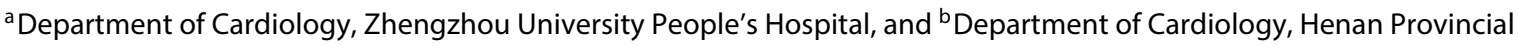 \\ Chest Hospital, Zhengzhou, and ' Department of Cardiology Henan Medical College, Xinzheng, PR China
}

For editorial comment see p. 186

\section{Key Words}

Renal denervation · Sympathetic nerve activity ·

Hypertension

\begin{abstract}
Objectives: This study was designed to observe the efficacy and safety of renal denervation from the inside and outside of renal arteries. Methods: Fourteen beagles were randomly divided into a control group $(n=4)$ and treatment group $(n=$ 10). One renal artery in every beagle of the treatment group was randomly assigned to an intimal group (10 renal arteries) which underwent percutaneous renal denervation from the inside, and another renal artery was assigned to an adventitial group (10 renal arteries) which underwent renal denervation from the outside by laparotomy. Results: Compared with the intimal group, the renal norepinephrine (NE) concentration in the adventitial group had significantly decreased $(p=0.003)$ at 3 months postsurgery. Renal artery HE staining showed that the perineurium from the adventitial group appeared thickened. Western blotting showed that renal tissue tyrosine hydroxylase (TH) protein expression in the adventitial group was significantly lower than that in the intimal group $(p<0.01)$ at 3 months postsurgery. There was a renal artery stenosis and a renal atrophy in the intimal group after 1 month of follow-up. Conclusion: The inhibi-
\end{abstract}

(C) 2015 S. Karger AG, Basel

0008-6312/15/1313-0189\$39.50/0 tory effect on renal sympathetic nerve activity was more effective in the adventitial group than the intimal group, and renal denervation in the former group was safe.

๑) 2015 S. Karger AG, Basel

\section{Introduction}

Hypertension affected approximately 1 billion of the global adult population in 2000 and its prevalence is predicted to rise to 1.5 billion hypertensive patients in 2025 [1]. Hypertension strikingly increases the risk of ischemic heart disease, heart failure, stroke and kidney disease [2]. Although multiple strategies such as a healthy lifestyle, exercise, diet modification and all the available antihypertensive medications are used for hypertension management, there is a special type regarded as resistant hypertension that is defined when a patient taking three or more antihypertensive drugs, including a diuretic, at optimal tolerated doses, maintains blood pressure values $>140 / 90 \mathrm{~mm} \mathrm{Hg}[3,4]$. Compared to hypertension which is under control, resistant hypertension increases the risk of myocardial infarction, con-

M.B. and C.Y. contributed equally to this work.

\section{KARGER 125}

E-Mail karger@karger.com

www.karger.com/crd
Chuanyu Gao, $\mathrm{PhD}$

Department of Cardiology

Zhengzhou University People's Hospital

7 Wei Wu Road, 450003 Zhengzhou (PR China)

E-Mail gaocyzzu@126.com 
gestive heart failure, stroke, chronic kidney disease and death [5].

Recently, a new approach known as catheter-based renal denervation to selectively disrupt renal sympathetic nerves from the intima of renal arteries has been developed. This involves ablation of both afferent and efferent renal sympathetic nerves mostly located in the adventitia of renal arteries in a mesh-like pattern [6]. The method has been shown to reduce renal sympathetic nerve activity and produce substantial blood pressure lowering in patients with resistant hypertension [4, 7-11].

Despite the moderate efficacy of catheter-based renal denervation from the intima of renal arteries, there are some limitations associated with the use of thermal injury traversing the intimal and medial layers of the renal artery in order to create thermal injury to the sympathetic nerves that may run from 2 to $10 \mathrm{~mm}$ deep from the intimal surface [12-14]. Firstly, in the Symplicity HTN-1 study, the proportion who achieved target systolic blood pressure (SBP) values $<140 \mathrm{~mm} \mathrm{Hg}$ only accounted for 38,39 and $50 \%$ at 12,24 and 36 months after the renal denervation, respectively $[15,16]$. The Symplicity HTN2 study has also shown that $39 \%$ patients achieved a target of $<140 \mathrm{~mm} \mathrm{Hg}$ in SBP within 6 months of renal denervation [7]. Secondly, in the same study, 6 of 45 treated patients (13\%) were nonresponders, defined as a failure to reduce blood pressure by at least $10 \mathrm{~mm} \mathrm{Hg}$, after 12 months following renal denervation. The proportion of nonresponders in the Symplicity HTN-2 study was $16 \%$. Thirdly, there was no statistical difference in the average number of antihypertensive medications after renal denervation during follow-up. In addition, there appeared to be no significant effect on office or 24-hour ambulatory SBP levels as compared to the control group in the study [17]. There is a need to develop and evaluate more effective methods to perform renal denervation.

Given the potential limitations of renal denervation from the intima of renal arteries and the distribution of renal sympathetic nerves being mostly located in the adventitia, we have evaluated the method of renal denervation from the adventitia of renal arteries by surgical procedure. The purpose of this study was to compare the efficacy and safety of intimal and adventitial denervation in suppressing renal sympathetic nerve activity in a beagle model.

\section{Materials and Methods}

Animals

This protocol was approved by the Institutional Laboratory Care and Use Committee and was conducted in accordance with regulatory guidelines for the care of laboratory animals. Fourteen beagles (12-14 months old, weight $10 \pm 0.5 \mathrm{~kg}$ ), which were provided by Yangzhou Quartet of Laboratory Animal Technology Co. Ltd. (Jiangsu, China), were used to assess the efficacy and safety of renal denervation from the intima and the adventitia of renal arteries in suppressing renal sympathetic nerve activity. This was done by assessing norepinephrine (NE) and tyrosine hydroxylase $(\mathrm{TH})$ concentrations in the renal parenchyma as well as histological changes in the renal sympathetic nerves. The 14 beagles were randomly divided into a control group (4 beagles) and treatment group (10 beagles). One renal artery of every beagle in the treatment group was randomly assigned to the intimal group (10 renal arteries), and another renal artery was assigned to the adventitial group (10 renal arteries). The control group only underwent renal arterial angiography, the arteries in the intimal group underwent percutaneous renal denervation from the inside after renal arterial angiography, and the arteries in the adventitia group underwent renal denervation from the outside after renal arterial angiography by laparotomy. A renal arterial angiography was performed at 1 and 3 months of followup, and the renal sympathetic nerve activity substances were analyzed.

The beagles were fasted overnight before the surgery. Then the animals were administered atropine $(0.05 \mathrm{mg} / \mathrm{kg})$ by intravenous injection, anesthetized with pentobarbital sodium $(15-30 \mathrm{mg} / \mathrm{kg}$; Merck, Darmstadt, Germany) by intravenous injection, which was supplemented when needed during the experiment. Cefuroxime sodium $(100 \mathrm{mg} / \mathrm{kg})$ was administered by intravenous perfusion during the surgery. The beagles were placed in a supine position and their surroundings were covered with sterile drapings. Routine clinical monitoring was performed during the procedure. A femoral artery was accessed using the Seldinger technique, and a 6-french introducer sheath was put in place. Intravenous heparin was administered $(60 \mathrm{U} / \mathrm{kg})$. The angiography of each renal artery was performed using a 6-french JR4.0 guiding catheter (Medtronic, Fridley, Minn., USA). We applied a cardiac radiofrequency ablation catheter (Biosense Webster, Diamond Bar, Calif., USA) for discrete radiofrequency ablations of $8 \mathrm{~W}$ or less and lasting up to 2 min each to obtain up to six ablations separated both longitudinally and rotationally from the inside of renal arteries in the intimal group. The surgical procedure for renal denervation was similar to the rat experiment of Jacob et al. [18]. An abdominal midline incision was performed to separate and expose the renal arteries of the adventitial group. A cardiac radiofrequency ablation catheter was then applied to ablate the adventitia from the outside, also of $8 \mathrm{~W}$ or less and lasting up to 2 min each to obtain up to six ablations separated both longitudinally and rotationally, which was the same as the ablation of renal arteries in the intimal group (fig. 1). After the surgery, gentamicin sulfate $(10 \mathrm{mg} / \mathrm{kg})$ was administered intramuscularly for 3 days.

Follow-up renal arterial angiography was performed to identify stenoses, thrombosis and any other abnormalities in renal arteries of 2 beagles in the control group and 5 beagles in the treatment group at 1 and 3 months, respectively. Immediately after follow-up renal arterial angiography, the beagles were heparinized and euthanatized in deep anesthesia. The renal vessels and kidneys were removed. These tissues were processed histologically. The section of renal artery was divided longitudinally into three equal parts and labeled as proximal, middle and distal segments. Three cross-sections (one each from the proximal, 

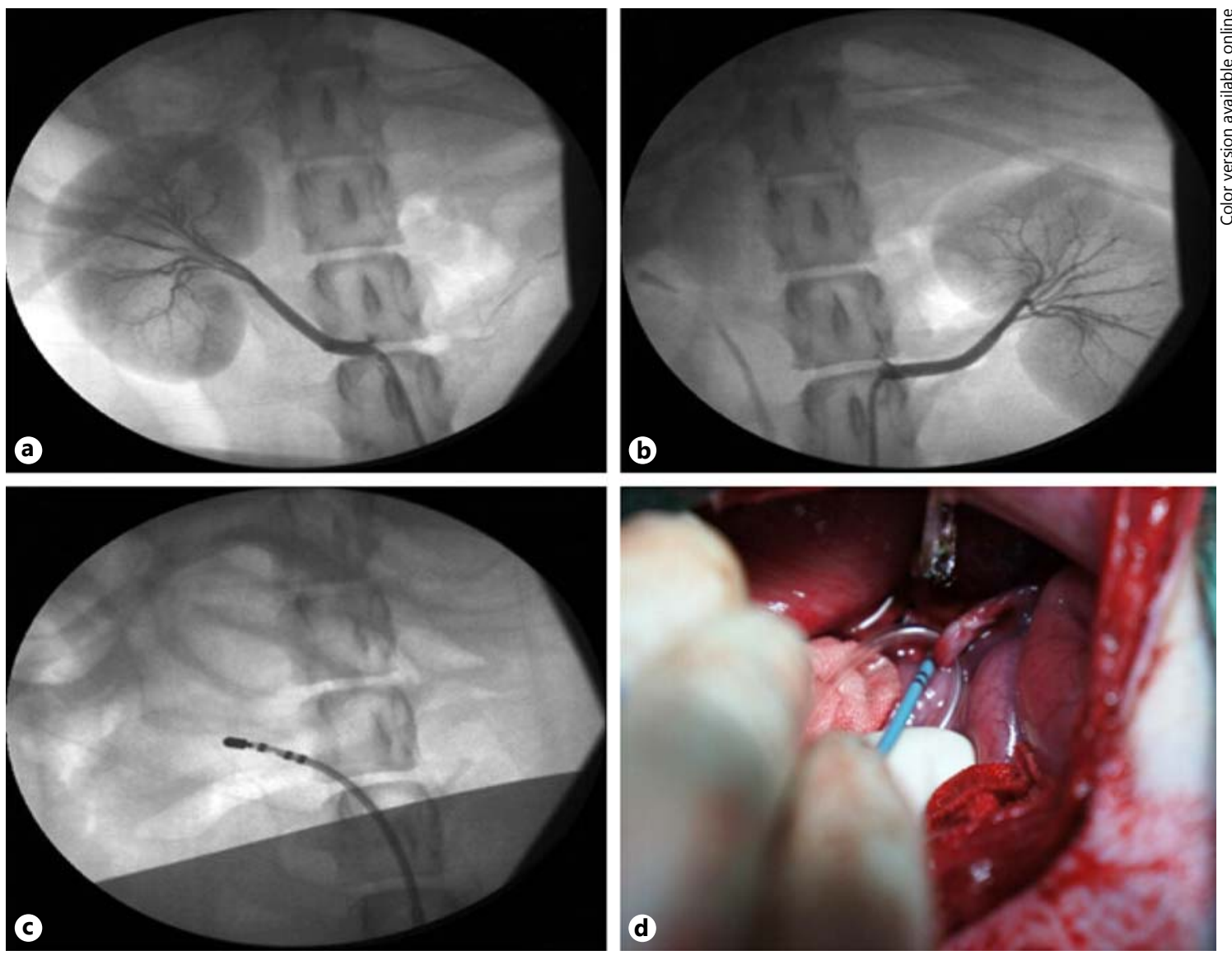

Fig. 1. Renal artery angiography and renal denervation by treatment group: left renal artery angiography in the intimal group (a); right renal artery angiography in the adventitial group (b); percutaneous renal denervation in the intimal group (c), and renal denervation by laparotomy in the adventitial group (d).

middle, and distal segments) were analyzed from each artery. Slides containing the renal vessels were stained with hematoxylin and eosin (HE). All renal arteries and perirenal connective tissue containing renal nerves surrounding each renal artery were examined grossly. The renal parenchyma was also examined for any evidence of thromboemboli, infarcts and inflammation. An independent, experienced pathologist reviewed the histological slides of the renal artery. From the top down, kidneys were cut into three sections and each section was weighed, placed in the freezing tube, immediately frozen in liquid nitrogen and then stored at $-80^{\circ} \mathrm{C}$.

\section{NE ELISA Assay}

The effectiveness of renal sympathicolysis was assessed by determining the NE concentration in renal parenchyma. This was done using an ELISA kit as per the manufacturer's instructions (Cusabio, Wuhan, China).

\section{Western Blot}

The kidney was homogenated in RIPA (50 mM Tris, $150 \mathrm{~mm}$ $\mathrm{NaCl}, 0.5$ mm EDTA, 1 mM DTT, 1\% Triton X-100) using a Polytron homogenizer. The homogenates were heated to $100^{\circ} \mathrm{C}$ for
$5 \mathrm{~min}$ and centrifuged at $12,000 \mathrm{~g}$ for $2 \mathrm{~min}$ to remove cellular debris and insoluble materials. The protein concentration was detected with a BCA protein quantitation kit and proteins were stored at $-80^{\circ} \mathrm{C}$. Protein samples were solubilized in SDS-PAGE sample buffer and separated by SDS-PAGE using $10 \%$ polyacrylamide gels. Following electrophoresis, the proteins were transferred to a nitrocellulose membrane. The membrane was then blocked in 5\% nonfat milk in TBST buffer at room temperature for $1 \mathrm{~h}$. The membrane was incubated with an anti-TH (1:500) at $4{ }^{\circ} \mathrm{C}$ overnight and then with a secondary antibody $(1: 3,000)$ at room temperature for $1 \mathrm{~h}$. Following visualization, Quantity One software was employed to determine the optical density of the bands.

\section{Statistical Analysis}

Continuous data were expressed as means \pm standard deviation and the differences were analyzed with one-way analyses of variance (normal distribution) or the Mann-Whitney U test (abnormal distribution or unequal variances). Statistical significance was considered to be $\mathrm{p}<0.05$ among the three groups and $\mathrm{p}<0.0167$ between two groups. All statistical analyses were performed with SPSS 17.0 software (SPSS Inc., Chicago, Ill., USA). 


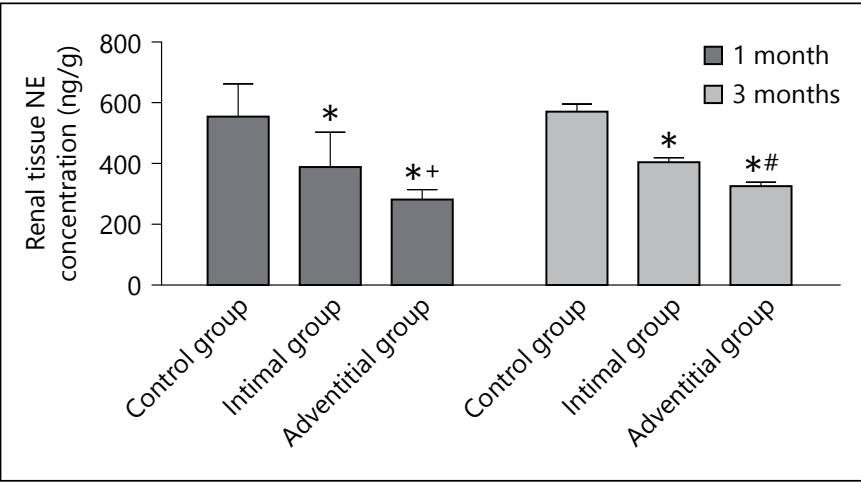

Fig. 2. Bar graph showing the effect of intimal and adventitial denervation upon the renal tissue $\mathrm{NE}$ concentration at 1 and 3 months. Compared to the control group, ${ }^{*} \mathrm{p}<0.001$; compared to the intimal group, ${ }^{+} \mathrm{p}=0.015,{ }^{\#} \mathrm{p}<0.001$.

\section{Results}

\section{Renal Tissue NE Concentration}

Renal NE concentrations in the control group, intimal group and adventitial group were $554.556 \pm 108.091$, $388.438 \pm 114.397$ and $281.685 \pm 32.723 \mathrm{ng} / \mathrm{g}$, respectively, after 1 month of follow-up. As compared to the control group, renal NE concentrations in the intimal group and adventitial group had significantly decreased ( $p=0.015$ and $\mathrm{p}<0.001$, respectively), and renal NE content in the adventitial group was significantly lower than that in the intimal group ( $\mathrm{p}=0.001)$. After 3 months of follow-up, renal NE concentrations in the control group, intimal group and adventitial group were $570.806 \pm 24.617$, $404.616 \pm 14.226$ and $325.561 \pm 12.989 \mathrm{ng} / \mathrm{g}$, respectively. Renal NE concentrations in the intimal group and adventitial group had also significantly decreased compared to that of the control group (both $\mathrm{p}<0.001$ ), and NE concentration in the adventitial group was significantly lower than that in the intimal group ( $\mathrm{p}=0.003$; fig. 2 ). Although the renal NE concentration of each group had increased at 3 months compared with that at 1 month, the change in renal NE concentration of the treatment group showed no significant difference at 1 and 3 months (all p > 0.05).

\section{Renal Artery HE Staining}

A normal nerve fascicle was surrounded by a thin fibrous connective tissue sheath (perineurium) in the control group. In contrast, the perineurium from the treatment group had thickened, and the perineurium appeared thicker in the vessels of the adventitial group (fig. 3). We found an example of intima thickening in the renal arteries of the intimal group after 3 months of fol- low-up. No intima thickening was found in the renal artery of the control group or adventitial group in the same period of follow-up (fig. 4).

\section{TH Protein Expression}

$\mathrm{TH}$ protein expression of renal tissue in the intimal and adventitial groups significantly decreased compared with the control group (both $\mathrm{p}<0.01$ ), and $\mathrm{TH}$ protein expression in the adventitial group was significant lower than that in the intimal group $(\mathrm{p}<0.01)$ at 1 month postsurgery. At 3 months after renal denervation, TH protein expression in the intimal group and adventitial group had also significantly decreased compared with the control group (both $\mathrm{p}<0.01$ ), and $\mathrm{TH}$ protein expression in the adventitial group was significantly lower than that of the intimal group ( $\mathrm{p}<0.01$; fig. 5, 6).

There was a renal artery stenosis and renal atrophy in the intimal group after 1 month of follow-up. Figure 7 shows renal artery tubular stenosis located in the proximal segment of a right renal artery, and the kidney connected with the renal artery stenosis revealed atrophy compared with the preoperative kidney. However, no renal artery stenosis and kidney atrophy in the same beagle were seen in the left renal artery which underwent renal denervation from the adventitia. The adventitial group had two minor adhesions between the renal artery and kidney after 1 month of follow-up. No serious adverse events occurred within 3 months in the other animals.

\section{Discussion}

In the 1930s, nonselective surgical sympathectomy was used for the treatment of malignant or severe hypertension. The interventional approach proved to be effective in reducing blood pressure and the results were maintained in the long term, and the survival rates were more than doubled in those undergoing sympathectomy, thus the benefits were evident in all stages of hypertension [19, 20]. Nevertheless, sympathectomy was abandoned in the 1960 s due to serious adverse effects $[21,22]$.

Renal denervation has been shown to be effective in the treatment of refractory and drug-resistant hypertension, and possibly in the treatment of some other conditions that may be driven by sympathetic overdrive, such as arrhythmias, heart failure, metabolic syndrome, central obstructive sleep apnea, chronic kidney disease and left ventricular hypertrophy [23-28]. However, renal denervation from the intima of the renal artery has some limitations associated with the use of transmural thermal 

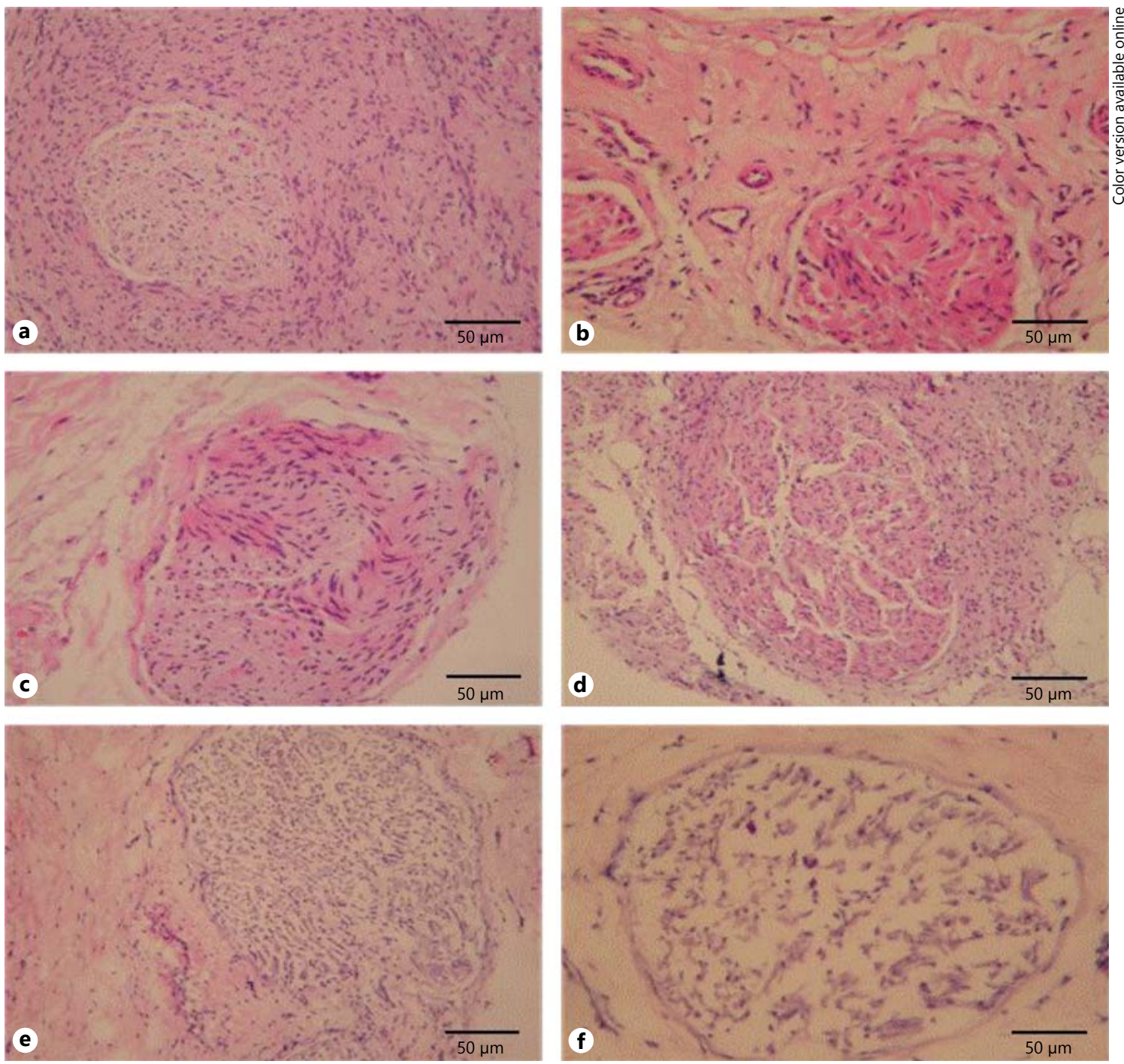

Fig. 3. HE staining of renal nerves of the vessels of each group: control group (a), intimal group (b) and adventitial group (c) at 1 month; control group (d), intimal group (e) and adventitial group (f) at 3 months.
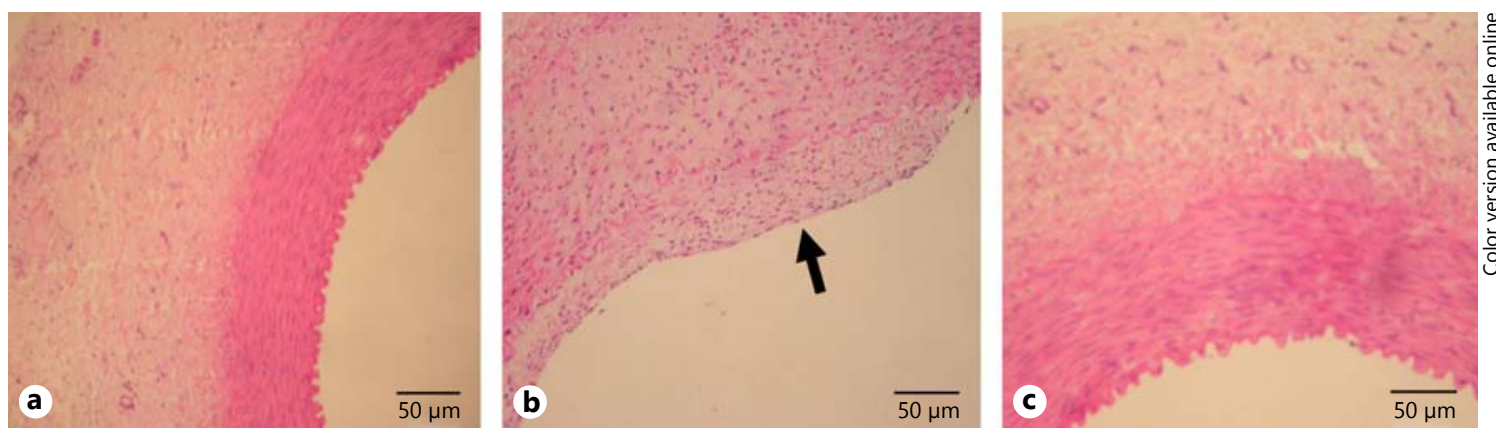

Fig. 4. An example of intima thickening in the intimal group at 3 months of follow-up (black arrow): control group (a), intimal group (b) and adventitial group (c) at 3 months. 


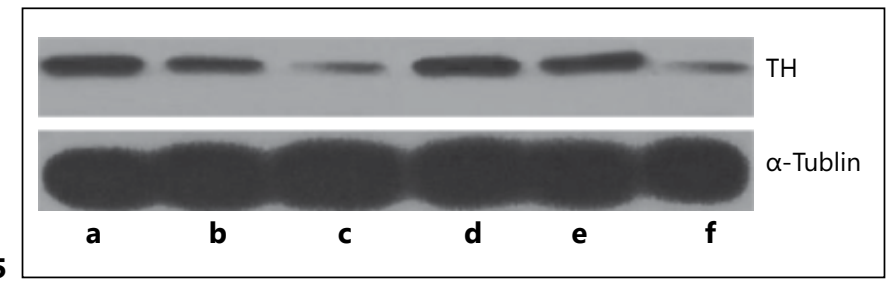

Fig. 5. The representative Western blot of $\mathrm{TH}$ normalized to a-tubulin: control group (a), intimal group (b) and adventitial group (c) at 1 month; control group (d), intimal group (e) and adventitial group (f) at 3 months.

Fig. 6. Bar graph showing the effect of intimal and adventitial denervation upon renal parenchymal TH levels at 1 and 3 months. Compared to the control group, ${ }^{*} \mathrm{p}<0.001$; compared to the intimal group, ${ }^{\#} \mathrm{p}<0.001$.

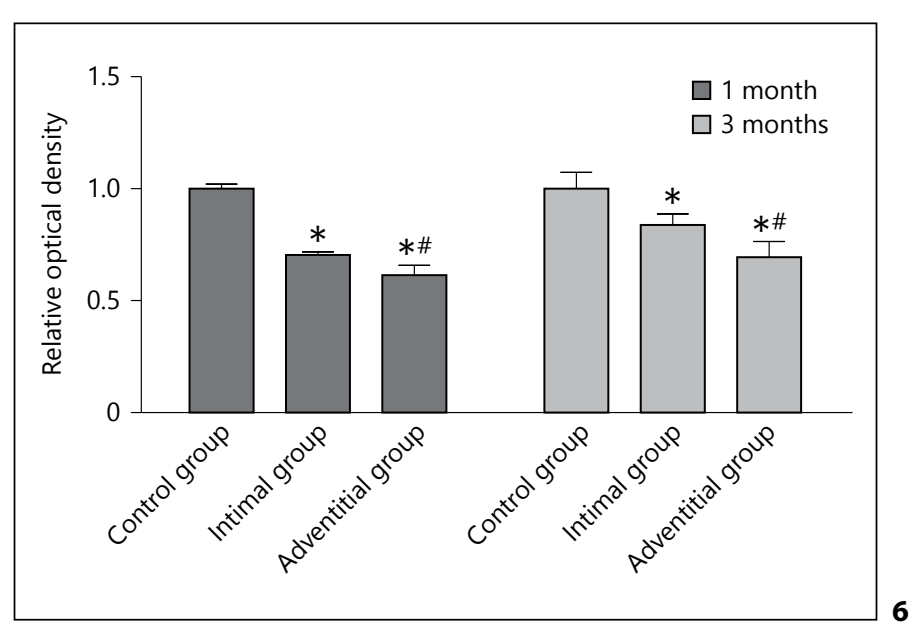

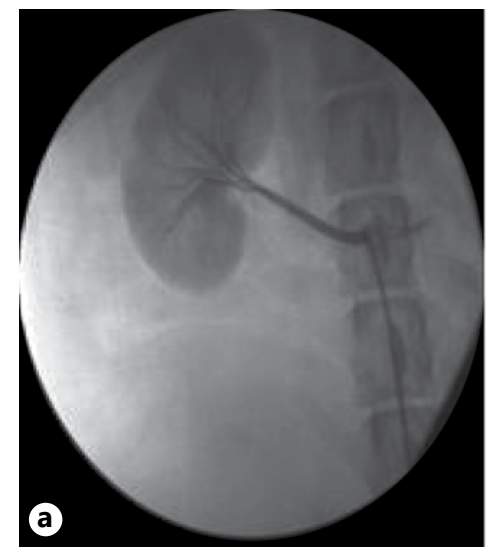
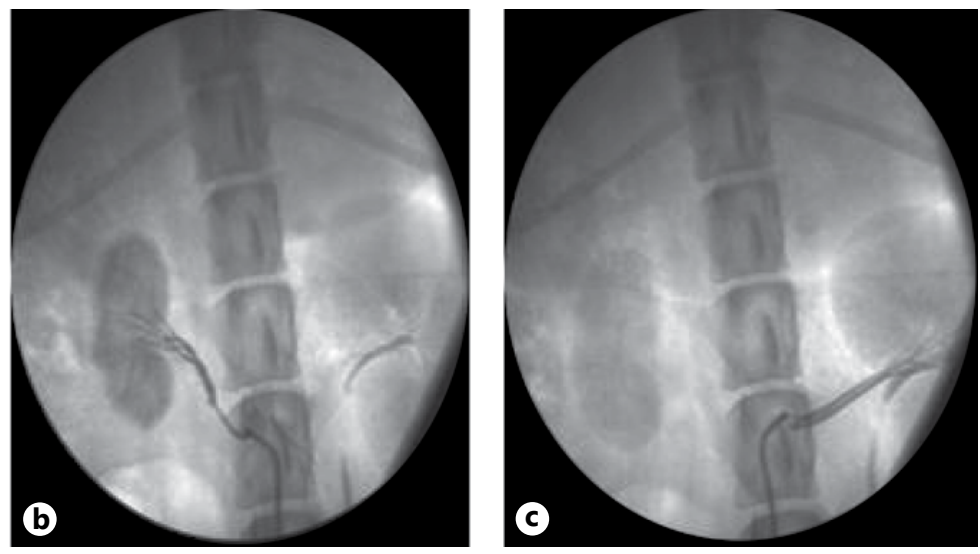

Fig. 7. Renal arterial angiography of the same beagle after 1 month of follow-up: intimal group before (a) and after (b) renal denervation; adventitial group after renal denervation (c).

injury traversing the intimal and medial layers of the renal artery in order to create thermal injury to the sympathetic nerves that may run from 2 to $10 \mathrm{~mm}$ deep from the intimal surface $[12,13,29]$.

In this study we selectively ablated the renal sympathetic nerves from the outside of arteries, and demonstrated the efficacy and safety of renal denervation from the adventitia of renal arteries via a laparotomy operation to achieve circumferential sympathetic nerve ablation with minimal injury to the renal artery intimal and medial layers. This has a number of potential advantages over renal denervation from the intima of the renal artery. It was possible to verify the significance of nerve injury by the assessment of NE concentration in the renal parenchyma after removal of the kidney at autopsy. It was demonstrated that renal denervation could reduce the NE concentration in the kidney. In a clinical study of catheter-based radiofrequency ablation the mean reduction in renal NE spillover was $47 \%$ [4]. MR-guided periarterial ethanol injection also found a significant reduction of $\mathrm{NE}$ concentration in the kidney parenchyma of 53\% [30]. Circumferential adventitial delivery of $0.15,0.30$ and 0.60 $\mathrm{ml}$ of ethanol injection caused a mean renal NE reduction of 54,78 and $88 \%$, respectively [31]. The present study showed that renal denervation from the intima and adventitia of renal arteries caused a mean renal NE reduction of 39 and $49 \%$ at 1 month, and 29 and $43 \%$ at 3 months, respectively, which demonstrated that the nerve injury of renal denervation from the adventitia was worse than that from the intima of renal arteries.

$\mathrm{TH}$ is the rate-limiting enzyme involved in catecholamines synthesis within the postganglionic nerve termi- 
nals; therefore, changes in TH have been used as a marker of sympathetic activity and have been extensively used to mark postganglionic sympathetic terminals innervating vessels and tissues [32-34]. TH and NE concentration with sympathetic activity in different experimental conditions support the proposition that changes in $\mathrm{TH}$ and $\mathrm{NE}$ concentration may reflect changes in sympathetic activity $[35,36]$. The present study showed that TH concentration in the adventitial group was lower than that in the intimal group, which also demonstrated that nerve injury in renal denervation from the adventitia was worse than from the intima.

In the present study the renal arterial HE staining demonstrated circumferential renal sympathetic nerve damage in the treatment group. However, the renal sympathetic nerve damage in surgical renal denervation from the adventitia was worse than that from the intima. In other animal experiments renal denervation could also cause renal sympathetic nerve damage by different interventions, such as MR-guided periarterial ethanol injection [37].

Four patients showed renal artery stenosis in 3 years of follow-up in the Symplicity HTN-1 study [16]. Templin et al. [38] found that optical coherent tomography detected endothelial injury and demonstrated local tissue damage at the ablation site with vasospasm, edema and thrombus formation, as well as diffuse renal artery constriction immediately after renal denervation from the intima. Cordeanu et al. [39] found neointimal thickening resulting in artery stenosis following renal sympathetic denervation from the intima. Our study also found neointimal thickening and artery stenosis after renal denervation from the inside of the renal artery; but renal artery stenosis was not found in the rest of the renal arteries, which showed a superiority of renal denervation from the adventitia. In terms of efficacy and safety, renal denervation from the adventitia offers some potential advantages over renal denervation from the intima. It is more effective and safe to reduce the renal sympathetic nerve activity. The process of separating the renal artery before renal denervation from the adventitia could cut perivascular nerves located on the outside of the renal artery, which were not likely to be damaged by catheter-based radiofrequency ablation.

\section{Study Limitations}

It is difficult to measure renal sympathetic nerve activity, which the clinical technique of determining NE spillover measurement may help to estimate. However, we measured NE concentration in renal tissue in vitro and did not determine NE spillover measurement. Since we

studied healthy beagles with only bilateral denervation by two different methods, we did not monitor BP change and did not set up a sham-operated group. The sample size of this study was not large enough, follow-up duration was not long enough, and differences between normotensive animals and hypertensive human subjects exist. The trauma as a result of renal denervation from the adventitia is large, and the cost may be high if we apply the method in patients. It is therefore necessary to search for other methods of renal denervation from outside the renal artery, such as laparoscopic, high-intensity, focused ultrasound.

\section{Conclusion}

We have presented the first experimental results on comparing the efficacy and safety of renal denervation from the intima and the adventitia of renal arteries in a beagle model. The study showed that the inhibitory effect in the adventitial group on renal sympathetic nerve activity was more effective than that in the intimal group, and renal denervation from the adventitia of renal arteries was safe. However, renal denervation from the intima of renal arteries presents the risk of renal artery stenosis.

\section{Acknowledgments}

We are grateful to Dr. Wenli Zhao (Interventional Room, Zhengzhou University People's Hospital) and Zhengguo Liu (Department of Pathology, Zhengzhou University People's Hospital) for their helpful assistance.

\section{Conflict of Interest}

There is no potential conflict of interest. This research received no grant from any funding agency in the public, commercial or not-for-profit sectors.

References

Cardiology 2015;131:189-196 DOI: $10.1159 / 000381799$
1 Kearney PM, Whelton M, Reynolds K, Muntner P, Whelton PK, He J: Global burden of hypertension: analysis of worldwide data. Lancet 2005;365:217-223.

2 Dzau VJ, Antman EM, Black HR, Hayes DL, Manson JE, Plutzky J, Popma JJ, Stevenson $\mathrm{W}$ : The cardiovascular disease continuum validated: clinical evidence of improved patient outcomes: part I: pathophysiology and clinical trial evidence (risk factors through stable coronary artery disease). Circulation 2006;114:2850-2870.
Effects of Renal Denervation on Renal Sympathetic Nerve Activity in Dogs 
3 Krum H, Schlaich M, Whitbourn R, Sobotka PA, Sadowski J, Bartus K, Kapelak B, Walton A, Sievert H, Thambar S, Abraham WT, Esler M: Catheter-based renal sympathetic denervation for resistant hypertension: a multicentre safety and proof-of-principle cohort study. Lancet 2009;373:1275-1281.

4 Symplicity HTN-1 Investigators: Catheterbased renal sympathetic denervation for resistant hypertension: durability of blood pressure reduction out to 24 months. Hypertension 2011;57:911-917.

5 Daugherty SL, Powers JD, Magid DJ, Tavel HM, Masoudi FA, Margolis KL, O'Connor PJ, Selby JV, Ho PM: Incidence and prognosis of resistant hypertension in hypertensive patients. Circulation 2012;125:1635-1642.

6 Thomas G, Shishehbor MH, Bravo EL, Nally JV: Renal denervation to treat resistant hypertension: guarded optimism. Cleve Clin J Med 2012;79:501-510.

7 Esler MD, Krum H, Sobotka PA, Schlaich MP, Schmieder RE, Bohm M: Renal sympathetic denervation in patients with treatment-resistant hypertension (the Symplicity $\mathrm{HTN}-2$ Trial): a randomised controlled trial. Lancet 2010;376:1903-1909.

8 Esler MD, Krum H, Schlaich M, Schmieder RE, Bohm M, Sobotka PA: Renal sympathetic denervation for treatment of drug-resistant hypertension: one-year results from the Symplicity HTN-2 randomized, controlled trial. Circulation 2012;126:976-982.

9 Mahfoud F, Cremers B, Janker J, Link B, Vonend O, Ukena C, Linz D, Schmieder R, Rump LC, Kindermann I, Sobotka PA, Krum H, Scheller B;Schlaich M, Laufs U, Bohm M: Renal hemodynamics and renal function after catheter-based renal sympathetic denervation in patients with resistant hypertension. Hypertension 2012;60:419-424.

10 Krum H, Sobotka P, Mahfoud F, Bohm M, Esler M, Schlaich M: Device-based antihypertensive therapy: therapeutic modulation of the autonomic nervous system. Circulation 2011;123:209-215.

11 Whitworth JA: 2003 World Health Organization (WHO)/International Society of Hypertension (ISH) statement on management of hypertension. J Hypertens 2003;21:19831992.

12 Cook S, Goy JJ, Togni M: Optical coherence tomography findings in renal denervation. Eur Heart J 2012;33:2992.

13 Kaltenbach B, Id D, Franke JC, Sievert H, Hennersdorf M, Maier J, Bertog SC: Renal artery stenosis after renal sympathetic denervation. J Am Coll Cardiol 2012;60:2694-2695.

14 Vonend O, Antoch G, Rump LC, Blondin D: Secondary rise in blood pressure after renal denervation. Lancet 2012;380:778.

15 Prugger C, Keil U, Wellmann J, de Bacquer D, de Backer G, Ambrosio GB, Reiner Z, Gaita D, Wood D, Kotseva K, Heidrich J: Blood pressure control and knowledge of target blood pressure in coronary patients across
Europe: results from the EUROASPIRE III survey. J Hypertens 2011;29:1641-1648.

16 Krum H, Schlaich MP, Sobotka PA, Bohm M, Mahfoud F, Rocha-Singh K, Katholi R, Esler MD: Percutaneous renal denervation in patients with treatment-resistant hypertension: final 3-year report of the Symplicity HTN-1 study. Lancet 2014;383:622-629.

17 Kandzari DE, Bhatt DL, Sobotka PA, O’Neill WW, Esler M, Flack JM, Katzen BT, Leon MB, Massaro JM, Negoita M, Oparil S, RochaSingh K, Straley C, Townsend RR, Bakris G: Catheter-based renal denervation for resistant hypertension: rationale and design of the SYMPLICITY HTN-3 Trial. Clin Cardiol 2012;35:528-535.

18 Jacob F, Ariza P, Osborn JW: Renal denervation chronically lowers arterial pressure independent of dietary sodium intake in normal rats. Am J Physiol Heart Circ Physiol 2003; 284:2302-2310.

19 Smithwick RH: Hypertensive vascular disease: results of and indications for splanchnicectomy. J Chronic Dis 1955;1:477-496.

20 Huan Y, Cohen DL: Renal denervation: a potential new treatment for severe hypertension. Clin Cardiol 2013;36:10-14.

21 Cohen DL, Townsend RR: Renal denervation revisited: promising treatment for resistant hypertension? J Clin Hypertens 2011;13:931-932.

22 Krum H, Schlaich M, Sobotka P, Scheffers I, Kroon AA, Leeuw PWD: Novel procedureand device-based strategies in the management of systemic hypertension. Eur Heart J 2011;32:537-544.

23 Linz D, Mahfoud F, Schotten U, Ukena C Hohl M, Neuberger HR, Wirth K, Bohm M: Renal sympathetic denervation provides ventricular rate control but does not prevent atrial electrical remodeling during atrial fibrillation. Hypertension 2013;61:225-231.

24 Sobotka PA, Krum H, Bohm M, Francis DP Schlaich MP: The role of renal denervation in the treatment of heart failure. Curr Cardiol Rep 2012;14:285-292.

25 Schlaich MP, Hering D, Sobotka P, Krum H, Lambert GW, Lambert E, Esler MD: Effects of renal denervation on sympathetic activation, blood pressure, and glucose metabolism in patients with resistant hypertension. Front Physiol 2012;3:10.

26 Linz D, Mahfoud F, Schotten U, Ukena C, Neuberger HR, Wirth K, Bohm M: Renal sympathetic denervation suppresses postapneic blood pressure rises and atrial fibrillation in a model for sleep apnea. Hypertension 2012;60:172-178

27 Hering D, Mahfoud F, Walton AS, Krum H, Lambert GW, Lambert EA, Sobotka PA, Bohm M, Cremers B, Esler MD, Schlaich MP: Renal denervation in moderate to severe CKD. J Am Soc Nephrol 2012;23:1250-1257.

28 Brandt MC, Mahfoud F, Reda S, Schirmer SH, Erdmann E, Bohm M, Hoppe UC: Renal sympathetic denervation reduces left ventricular hypertrophy and improves cardiac function in patients with resistant hypertension. J Am Coll Cardiol 2012;59:901-909.

29 Doumas M, Douma S: Interventional management of resistant hypertension. Lancet 2009;373:1228-1230.

30 Streitparth F, Walter A, Stolzenburg N, Heckmann L, Breinl J, Rinnenthal JL, Beck A, De Bucourt M, Schnorr J, Bernhardt U, Gebauer B, Hamm B, Gunther RW: MR-guided periarterial ethanol injection for renal sympathetic denervation: a feasibility study in pigs. Cardiovasc Intervent Radiol 2013;36: 791-796.

31 Fischell TA, Vega F, Raju N, Johnson ET, Kent DJ, Ragland RR, Fischell DR, Almany SL, Ghazarossian VE: Ethanol-mediated perivascular renal sympathetic denervation: preclinical validation of safety and efficacy in a porcine model. EuroIntervention 2013;9: 140-147.

32 Long JB, Segal SS: Quantifying perivascular sympathetic innervation: regional differences in male C57BL/6 mice at 3 and 20 months. J Neurosci Methods 2009;184:124-128.

33 Damon DH: TH and NPY in sympathetic neurovascular cultures: role of LIF and NT-3. Am J Physiol Cell Physiol 2008;294:306-312.

34 Burgi K, Cavalleri MT, Alves AS, Britto LR, Antunes VR, Michelini LC: Tyrosine hydroxylase immunoreactivity as indicator of sympathetic activity: simultaneous evaluation in different tissues of hypertensive rats. Am J Physiol Regul Integr Comp Physiol 2011;300: 264-271.

35 Morrison JF, Pallot DJ, Sheen R, Dhanasekaran S, Mensah-Brown EP: The effects of age and streptozotocin diabetes on the sympathetic innervation in the rat penis. Mol Cell Biochem 2007;295:53-58.

36 Parrish DC, Gritman K, van Winkle DM Woodward WR, Bader M, Habecker BA: Postinfarct sympathetic hyperactivity differentially stimulates expression of tyrosine hydroxylase and norepinephrine transporter. Am J Physiol Heart Circ Physiol 2008;294: 99-106.

37 Rippy MK, Zarins D, Barman NC, Wu A, Duncan KL, Zarins CK: Catheter-based renal sympathetic denervation: chronic preclinical evidence for renal artery safety. Clin Res Cardiol 2011;100:1095-1101.

38 Templin C, Jaguszewski M, Ghadri JR, Sudano I, Gaehwiler R, Hellermann JP, Schoenenberger-Berzins R, Landmesser U, Erne P, Noll G, Luscher TF: Vascular lesions induced by renal nerve ablation as assessed by optical coherence tomography: pre- and post-procedural comparison with the Simplicity catheter system and the EnligHTN multi-electrode renal denervation catheter. Eur Heart J 2013;34: 2141-2148.

39 Cordeanu ME, Gaertner S, Bronner F, Jahn C, Prinz E, Hannedouche T, Stephan D: Neointimal thickening resulting in artery stenosis following renal sympathetic denervation. Int J Cardiol 2014;177:117-119. 